\title{
Visual assessment of colorectal flat and depressed lesions by using narrow band imaging
}

\section{(ㄷ)(1) $\odot$}

Authors

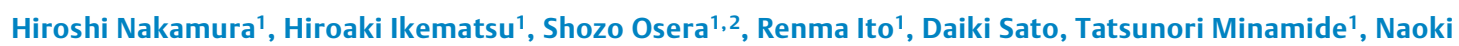
Okamoto $^{1}$, Yoichi Yamamoto ${ }^{1}$, Takuya Hombu ${ }^{1}$, Kenji Takashima ${ }^{1}$, Keiichiro Nakajo ${ }^{1}$, Tomohiro Kadota ${ }^{1}$, Yusuke Yoda $^{1}$, Keisuke Hori ${ }^{1}$, Yasuhiro Oono ${ }^{1}$, Tomonori Yano ${ }^{1}$

Institutions

1 Department of Gastroenterology and Endoscopy, National Cancer Center Hospital East, Chiba, Japan

2 Department of Gastroenterology, Saku Central Hospital Advanced Care Center, Nagano, Japan

submitted 15.3.2017

accepted after revision 8.9 .2017

\section{Bibliography}

DOI https://doi.org/10.1055/s-0043-120992 |

Endoscopy International Open 2017; 05: E1284-E1288

(c) Georg Thieme Verlag KG Stuttgart · New York ISSN 2364-3722

\section{Corresponding author}

Hiroaki Ikematsu, MD, Department of Gastroenterology and Endoscopy, National Cancer Center Hospital East, 6-5-1, Kashiwanoha, Kashiwa, Chiba, 277-8577, Japan Fax: 04-7134-6865

hikemats@east.ncc.go.jp

\section{ABSTRACT}

Background and study aims Visual assessment of laterally spreading tumors non-granular type (LST-NG) and depressed lesions by narrow band imaging (NBI) without magnification has not been studied. We investigated the role of non-magnifying NBI in detecting LST-NG and type Ilc lesions on colonoscopy.

Patients and methods This retrospective study examined consecutive patients diagnosed as having LST-NG and/or type Ilc lesions in our hospital between August 2011 and July 2013. These lesions were classified as "Brownish area (BA)," "Brown only in the margins (O-ring sign)," "Same color as the normal mucosa (SC)," and "Whitish area (WA)" based on their appearance on non-magnifying NBI, and their appearance were compared with their histopathological findings.

Results A total of 18 type Ilc and 180 LST-NG lesions were analyzed. Among the type Ilc lesions, 5 (28\%), 12 (67\%), and 1 (5\%) were classified as BA, O-ring sign, and SC, respectively. Among the LST-NG lesions, 126 (70\%), 26 (14\%), and 28 lesions (16\%) were classified as BA, O-ring sign, and SC, respectively. The Ilc lesions were found to have 1 lesion (20\%) with high-grade dysplasia (HGD) in the $\mathrm{BA}$, and 2 lesions (17\%) with invasive cancer (IC) in the Oring sign group. Among the LST-NG lesions, 27 (21\%) were found to have IC and 49 (39\%), HGD in the BA group; 8 lesions (31\%) had IC and 4 (15\%) had HGD in the O-ring sign group; and 1 lesion (4\%) had IC and 4 (14\%) had HGD in the SC group.

Conclusions Most flat and depressed colorectal lesions were seen on non-magnifying NBI as brown lesions with the exception of some flat lesions that were indistinguishable in color from the adjacent normal mucosa. Some of these flat lesions were also found to have HGD or IC.

\section{Introduction}

Colonoscopy is the gold standard investigation for detection and treating adenomatous polyps as it allows for therapeutic polypectomy, and therefore results in a reduction in colorectal cancer-related deaths [1]. Adenomatous polyps are missed in about $10 \%$ to $30 \%$ of cases with conventional endscopy using white light imaging (WLI) [2-5]. This is explained by 2 possible reasons: first, lesions located behind mucosal folds may be missed as these folds create blind spots for the endoscope [6]; sec- ond, among the different macroscopic type of adenomas, flat and depressed lesions are difficult to detect with standard WLI endoscopy [7]. Novel endoscopy innovations such as Third Eye, full-spectrum endoscopy (FUSE), and G-EYE endoscopy, and endoscopic devices like EndoRings have reduced the missed lesions rates for lesions that are hidden by mucosal folds [ $8-11]$. With respect to flat and depressed lesions, image-enhanced endoscopy (IEE) techniques such as narrow band imaging (NBI) have proven to be efficacious in detecting superficial squamous 
cell carcinoma in the head and neck region and in the esophagus [12]. However, the utility of NBI in effectively evaluating colorectal lesions is controversial. One meta-analysis failed to demonstrate any reduction in adenoma miss rate or improvement in detection of flat lesions with NBI compared to WLI [13]. Conversely, another meta-analysis concluded that NBI increased detection of flat adenomas [14]. Moreover, NBI did not improve visibility of colorectal flat lesions [15]. There are no studies describing the visibility of depressed lesions with use of NBI. Depressed and flat type colorectal lesions, especially laterally spreading tumor non-granular type (LST-NG), are known to have higher malignant potential $[16,17]$.

In this study, we assessed visibility of LST-NG and depressed lesions by using NBI and analyzed the association between their appearance and histology.

\section{Patients and methods}

\section{Subjects}

This retrospective study included consecutive patients diagnosed with LST-NG and/or depressed lesions that were detected endoscopically or surgically resected in the National Cancer Center Hospital East between August 2011 and July 2013. All included cases satisfied the following criteria: 1 ) the lesion was an epithelial neoplasm; and 2) endoscopic imaging of the lesions were visible on non-magnifying NBI. Depressed lesions were classified as macroscopic type 0 -Ilc according to the Paris endoscopic classification [18]. LST refers to the lateral growth of neoplastic lesions at least $10 \mathrm{~mm}$ in diameter. In LST lesions, LST-NG defined as with smooth surface [19].

The study protocol was approved by the institutional review board of the National Cancer Center on November 12, 2016 (approval number 2016-271, dated 12 Nov 2016) and conformed to the provisions of the Declaration of Helsinki. All information was collected from the hospital database or patients' medical records.

\section{Endoscopic equipment and setting}

All procedures were performed with EVIS LUCERA SPECTRUM and EVIS LUCERA ELITE systems (Olympus, Optical Co., Ltd., Tokyo, Japan) and colonoscopes CF-H260AZI, PCF-Q260AZI, and PCF-Q240ZI (Olympus Optical Co., Tokyo, Japan). The NBI settings were fixed at a surface structure enhancement level of A8 with an adaptive hemoglobin color index enhancement level of 3 .

\section{Colonoscopy procedure}

For bowel preparation, 2 to $3 \mathrm{~L}$ of polyethylene glycol solution was administered in the morning on the day before the colonoscopy. All patients received scopolamine butylbromide $(10 \mathrm{mg})$ prior to the procedure intravenously. When patients complained of discomfort or pain, midazolam $(0.03 \mathrm{mg} / \mathrm{kg})$ and/or pethidine hydrochloride $(35 \mathrm{mg})$ was administered for conscious sedation.

\section{Diagnosis and treatment}

Qualitative diagnosis and diagnosis of invasion depth was estimated endoscopically in combination with conventional view, NBI diagnosis with magnification, and pit pattern diagnosis by magnifying chromoendoscopy before treatment [20,21]. If the lesions were identified as noninvasive neoplasms and carcinomas with minute $(<1000 \mu \mathrm{m})$ submucosal invasion, endoscopic resection was performed. The resections included either polypectomy, endoscopic mucosal resection (EMR), endoscopic piecemeal mucosal resection (EPMR), or endoscopic submucosal dissection (ESD). If the lesions were diagnosed as deep invasive cancer, surgical resection consisting of a curative resection with lymph node dissection was performed.

\section{Histological assessment}

Resected specimens were fixed with $10 \%$ neutral buffered formalin and embedded in paraffin. Thin $(3-\mu \mathrm{m})$ sections of the paraffin block were submitted for routine histopathological analysis. Histological diagnosis was performed according to the classification system of the World Health Organization by pathologists with expertise in the digestive tract [22].

\section{Retrospective image analyses}

Lesions were detected by using WLI in 240 series, on the other hand, the lesions were detected by using NBI in 260 series. For all included cases, NBI without magnification demonstrated the entire lesion. Based on their appearance, colorectal lesions were classified into 4 groups: Lesions that appeared entirely brown in color were defined as "Brownish area (BA)"; lesions that had brown color only along their margin were defined as "Brown only in the margins (O-ring sign)"; lesions with no color difference from the adjacent normal mucosa were defined as "Same color as the normal mucosa (SC)"; and lesions that were entirely white in color were defined as "Whitish area (WA)". Representative images of each of these groups are shown in Fig. 1. All lesions were independently classified by 3 endoscopists (H.I., S. O., H. N.), 2 of whom were senior consultants. In the event of any difference of opinion, the majority view was accepted. If all 3 endoscopists chose differently, the lesion was classified following a consultative discussion.

\section{Outcomes}

Data regarding classification of lesions based on visual appearance were described in numbers and percentages. The association between morphology and visibility was analyzed for LSTNG and Ilc lesions. Further, histopathological diagnosis of individual groups was compared for LST-NG and IIc lesions.

\section{Results}

A total of 180 LST-NG lesions (146 patients) and 18 type Ilc lesions (16 patients) were analyzed. The patient and lesion characteristics are presented in > Table 1 . Of the 180 LST-NG lesions, 115 (64\%) were detected in the right colon (cecum to transverse colon) and 65 (36\%) were in the left colon (descending and sigmoid colon) and rectum. Of the 18 type Ilc lesions, 9 


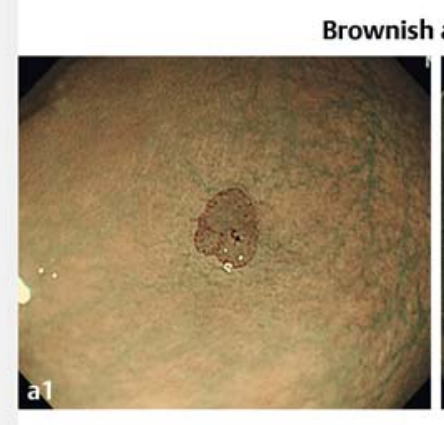

Same color as the normal mucosa (SC)

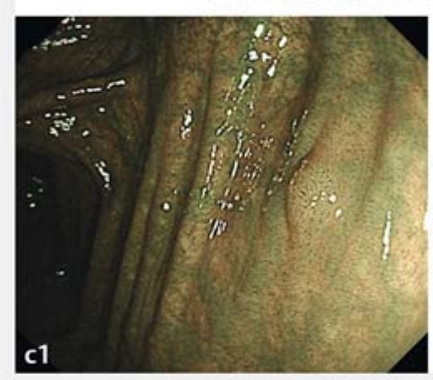

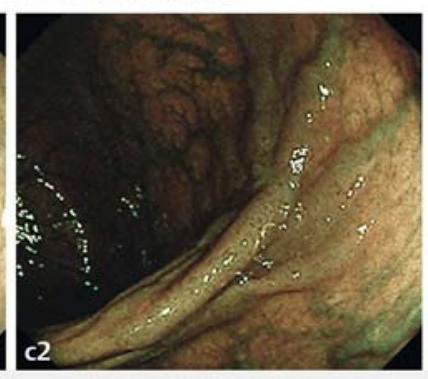

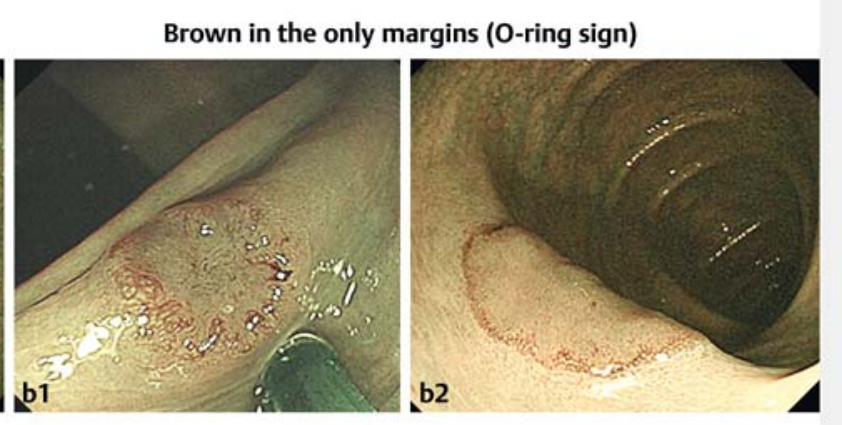

Whitish area (WA)

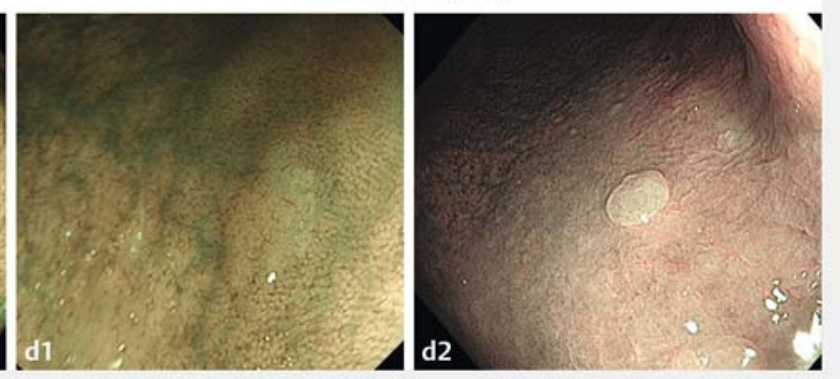

- Fig. 1 Classification of lesions based on their visual appearance on non-magnifying NBI. a Brownish area (BA): the entire lesion appears brown. The histology is low-grade dysplasia (a1) and high-grade dysplasia (a2). b Brown only in the margins (O-ring sign): only the margin of the lesion is brown in color. The histology is high grade dysplasia (b1, b2). c Same color as the normal mucosa (SC): the lesion is indistinguishable in color from the adjacent normal mucosa. The histology is low-grade dysplasia (c1) and high-grade dysplasia (c2). $\mathbf{d}$ Whitish area (WA): the entire lesion appears whitish in color. The histology is hyperplastic polyps (d1, d2).

- Table 1 Characteristics of patients and lesions.

\begin{tabular}{|l|c|c|}
\hline & LST-NG (n= 180) & Type Ilc (n= 18) \\
\hline Age, median (range), years & $69(34-84)$ & $73(51-82)$ \\
\hline Male sex, n & $130(72 \%)$ & $14(78 \%)$ \\
\hline Size, median (range), mm & $20(10-60)$ & $6(2-20)$ \\
\hline Location, $\mathrm{n}$ & & \\
\hline - right colon & $115(64 \%)$ & $9(50 \%)$ \\
\hline - left colon, rectum & $65(36 \%)$ & $9(50 \%)$ \\
\hline
\end{tabular}

- Table 2 Classification based on non-magnifying NBI images.

\begin{tabular}{|l|c|c|}
\hline & $\begin{array}{l}\text { LST-NG } \\
(\mathbf{n = 1 8 0 )}\end{array}$ & $\begin{array}{c}\text { Type Ilc } \\
(\mathbf{n = 1 8 )}\end{array}$ \\
\hline Brownish area (BA) & $126(70 \%)$ & $5(28 \%)$ \\
\hline Brown in the only margins (O-ring sign) & $26(14 \%)$ & $12(67 \%)$ \\
\hline Same color as the normal mucosa (SC) & $28(16 \%)$ & $1(5 \%)$ \\
\hline Whitish area (WA) & $0(0 \%)$ & $0(0 \%)$ \\
\hline
\end{tabular}

(50\%) were in the right colon and 9 (50\%) in the rectum. The number of LST-NG and type Ilc lesions that were visible with non-magnifying NBI endoscopy are presented in $>$ Table 2.
Based on their appearance on NBI, the LST-NG lesions were classified as follows: BA, 126 (70\%); O-ring sign, 26 (14\%); SC, 28 (16\%); and WA, none. Similarly, type Ilc lesions were classified as: BA, 5 (28\%); O-ring sign, 12 (67\%); SC, 1 (5\%); and WA, none. The total number of lesions classified as BA and O-ring sign by non-magnifying NBI were 152 (84\%) and 17 (94\%) among the LST-NG and IIc lesions, respectively.

The relationship between the visual appearance and the histopathological diagnosis of the lesions was analyzed. Changes identified as low-grade dysplasia (LGD), high-grade dysplasia (HGD), and invasive cancer (IC) were seen in 87 (48\%), 57 (32\%), and 36 (20\%), respectively, of LST-NG lesions. LGD was the most common histopathological finding in each of groups. The majority of HGD and IC were seen in the groups classified as BA and O-ring sign. Only 5 of these lesions were seen in the SC group ( $\triangleright$ Table 3 ). LGD, HGD, and IC were seen in 15 (83\%), 1 $(6 \%)$, and 2 lesions (11\%), respectively, of Ilc lesions. Among these lesions all HGD and IC changes were limited to the BA and O-ring signgroups ( $\triangleright$ Table 4 ).

\section{Discussion}

There are no published studies concerning the visual appearance of LST-NG, and IIc lesions. Identification of these lesions is important owing to their higher risk of malignant transformation. This study was undertaken to analyze their visual appearance and correlate the same with their histology. We used non- 
- Table 3 Visual appearance and pathology findings of LST-NG lesions.

\begin{tabular}{|l|l|l|l|}
\hline & $\begin{array}{l}\text { BA } \\
(\mathbf{n = 1 2 6})\end{array}$ & $\begin{array}{l}\text { O-ring sign } \\
(\mathbf{n = 2 6 )}\end{array}$ & $\begin{array}{l}\text { SC } \\
(\mathbf{n = 2 8 )}\end{array}$ \\
\hline Low-grade dysplasia & $50(40 \%)$ & $14(54 \%)$ & $23(82 \%)$ \\
\hline High-grade dysplasia & $49(39 \%)$ & $4(15 \%)$ & $4(14 \%)$ \\
\hline Invasive cancer & $27(21 \%)$ & $8(31 \%)$ & $1(4 \%)$ \\
\hline
\end{tabular}

- Table 4 Visual appearance and pathology findings of type llc lesions.

\begin{tabular}{|l|l|l|l|}
\hline & $\begin{array}{l}\text { BA } \\
(\mathbf{n = 5}\end{array}$ & $\begin{array}{l}\text { O-ring sign } \\
(\mathbf{n = 1 2 )}\end{array}$ & $\begin{array}{l}\text { SC } \\
\mathbf{( n = 1 )}\end{array}$ \\
\hline Low-grade dysplasia & $4(80 \%)$ & $10(83 \%)$ & $1(100 \%)$ \\
\hline High-grade dysplasia & $1(20 \%)$ & $0(0 \%)$ & $0(0 \%)$ \\
\hline Invasive cancer & $0(0 \%)$ & $2(17 \%)$ & $0(0 \%)$ \\
\hline
\end{tabular}

magnifying NBI to determine and compare the visual appearance of LST-NG and type Ilc lesions. In our study, on non-magnifying NBI, $16 \%$ of LST-NG and $5 \%$ of IIc lesions were found to be the same color as the adjacent normal mucosa. We think that is a very important finding, because lesions of the same color as the adjacent mucosa may be difficult to detect by non-magnifying NBI.

There are several studies aimed at reducing the miss rate of colorectal lesions on colonoscopy. Full-spectrum endoscopy (FUSE) is a novel colonoscopy technique that increases the maximum field of view to improve the detection of adenomas located behind mucosal folds and flexures. In a preliminary study, the adenoma miss rate was found to be significantly lower with FUSE (7\%) than with the standard forward-viewing endoscopy (41\%) [9]. Another novel endoscopy technique, G-EYE endoscopy, uses a balloon to increase the adenoma detection rate, and has been proven to have a lower adenoma miss rate (7.5\%) than standard colonoscopy (44.7\%) [10]. Each of these innovations resulted in a reduction in the adenoma miss rate. However, the previously mentioned studies do not specifically clarify if these techniques improved visualization of lesion morphology. Although they may improve the detection of lesions located in blind spots, it is also not specified if they improved the detection of flat and depressed lesions.

Flat and depressed lesions are considered as having greater malignant potential than other polypoid lesions owing to a higher incidence of HGD and IC $[17,23]$. Therefore, early detection of these lesions is crucial to patient survival. In the esophagus, NBI was demonstrated to be superior to WLI in detecting early-stage squamous cell carcinoma presenting as "almost flat" or "depressed" lesions because these lesions were clearly visible as brownish lesions [12]. The majority of reports about adenoma detection in the colorectal region, but the majority of the results were negative. The efficacy of NBI for the detection of flat lesions is controversial [13-15]. Further, there are no studies reporting on the role of NBI in detecting depressed lesions. In a study published by us, NBI did not improve adeno- ma detection rate, and although flat or depressed lesions were detected more frequently with NBI than WLI, the difference was not significant. In this study, it was not possible for us to evaluate the efficacy of NBI in detecting LST-NG and IIc lesions owing to the small number of these lesions [24]. Oka et al., in a retrospective study to determine whether autofluorescence imaging (AFI) and $\mathrm{NBI}$ improved the visibility of flat neoplastic lesions, evaluated endoscopic imaged without magnification of colorectal flat lesions. Since the AFI scores were greater than NBI scores, the authors concluded that AFI may be useful in improving the image quality of colorectal flat tumors [15]. Our previous study included classification of colorectal lesions into 4 groups based on their visual appearance. One group included lesions of the same color as normal colorectal mucosa, which may have posed difficulty in their detection. That may explain why NBI did not improve detection of colorectal lesions over WLI. In the current study, there were no lesions classified as WA. According to the NBI International Colorectal Endoscopic (NICE) classification, WA is considered an indicator of hyperplastic lesions and SSA/P. Because we only analyzed neoplastic lesions, it is understandable that none of the lesions were classified as WA [25].

Almost all type Ilc lesions (17/18) were classified in the BA and O-ring sign group, implying that NBI may improve their detection and identification. On the other hand, $16 \%$ of LST-NG lesions (28/180) were in the SA group, of which, 5 had HGD or IC. These lesions may be overlooked if $\mathrm{NBI}$ alone is relied upon. This is an important observation in light of knowledge that in the Japan Polyp Study, which was a multicenter, randomized, controlled trial designed to evaluate follow-up surveillance strategies, many LST-NG lesions were detected only after removal of all detected polyps [26]. This underscores the need for improvement in detection of these lesions.

Recent studies have demonstrated that the next-generation $\mathrm{NBI}$ system resulted in bright images, and was effective in detecting colorectal lesions $[27,28]$. Shimoda et al., in a randomized tandem trial, reported a significantly lower adenoma miss rate by using blue-laser imaging (BLI) [29]. Ikematsu et al., in a multicenter randomized controlled study, demonstrated that the mean number of adenomas per patients was significantly higher in the BLI group compared to the WLI group [30]. Further studies are necessary to evaluate their effectiveness in detecting flat and depressed lesions.

This study has several limitations. First, it is a retrospective study of non-magnifying NBI endoscopic images of lesions that did not involve comparison with WLI. In addition, the image quality for NBI, and therefore the detection of flat and depressed lesions, depends on adequate colonic preparation. Although the visual appearance of these lesions using NBI in this study did not influence their preparation, detection of these lesions will be influenced greatly. A prospective study is needed to overcome these discrepancies. Secondly, the information regarding the groups based on visual appearance is inadequate. Although we analyzed the association between the visual appearance and pathology of the lesions, we did not investigate the reasons for the differences in their appearance. We also 
did not study the inter-observer concordance rate of the visual appearance group.

\section{Conclusion}

In conclusion, this study demonstrated that colonoscopy with non-magnifying NBI identified most flat and depressed colorectal lesions as brown, with the exception of some flat lesions that appeared indistinguishable in color from the adjacent normal mucosa. Some of these flat lesions were found to have HGD or IC. Further studies are needed to evaluate the visibility of these lesions.

\section{Competing interests}

None

\section{References}

[1] Zauber AG, Winawer S], O'Brien M] et al. Colonoscopic polypectomy and long-term prevention of colorectal-cancer deaths. N Engl J Med 2012; 366: 687-696

[2] van Rijn JC, Reitsma JB, Stoker J et al. Polyp miss rate determined by tandem colonoscopy: a systematic review. Am J Gastroenterol 2006; 101: $343-350$

[3] Rex DK, Cutler CS, Lemmel GT et al. Colonoscopic miss rates of adenomas determined by back-to-back colonoscopies. Gastroenterology 1997; 112: $24-28$

[4] Heresbach D, Barrioz T, Lapalus MG et al. Miss rate for colorectal neoplastic polyps: a prospective multicenter study of back-to-back video colonoscopies. Endoscopy 2008; 40: 284-290

[5] Leufkens AM, van Oljen MG, Vleggar FP et al. Factors influencing the miss rate of polyps in a back-to-back colonoscopy study. Endoscopy 2012; 44: 470-475

[6] Pickhardt PJ, Nugent PA, Mysliwiec PA et al. Location of adenomas missed by optical colonoscopy. Ann Intern Med 2004; 141: 352 - 359

[7] Kudo S, Kashida H, Tamura T et al. Colonoscopic diagnosis and management of nonpolypoid early colorectal cancer. World J Surg 2000; 24: $1081-1090$

[8] Leufkens AM, DeMarco DC, Rastogi A et al. Effect of a retrogradeviewing device on adenoma detection rate during colonoscopy: the TERRACE study. Gastrointest Endosc 2011; 73: 480 - 489

[9] Gralnek LM, Siersema PD, Halpern Z et al. Standard forward-viewing colonoscopy versus full-spectrum endoscopy: an international, multicentre, randomised, tandem colonoscopy trial. Lancet Oncol 2014; 15: $353-360$

[10] Halpern Z, Gross SA, Gralnek IM et al. Comparison of adenoma detection and miss rates between a novel balloon colonoscope and standard colonoscopy: a randomized tandem study. Endoscopy 2015; 47: $238-244$

[11] Dik VK, Gralnek IM, Segol O et al. Multicenter, randomized, tandem evaluation of EndoRings colonoscopy-results of the CLEVER study. Endoscopy 2015; 47: $1151-1158$

[12] Muto M, Minashi K, Yano T et al. Early detection of superficial squamous cell carcinoma in the head and neck region and esophagus by narrow band imaging: a multicenter randomized controlled trial. J Clin Oncol 2010; 28: 1566 - 1572

[13] Pasha SF, Leighton JA, Das A et al. Comparison of the yield and miss rate of narrow band imaging and white light endoscopy in patients undergoing screening or surveillance colonoscopy: a meta-analysis. Am J Gastroenterol 2012; 107: 363 - 370; quiz 371

[14] Jin XF, Chai TH, Shi JW et al. Meta-analysis for evaluating the accuracy of endoscopy with narrow band imaging in detecting colorectal adenomas. J Gastroenterol Hepatol 2012; 27: 882 -887

[15] Oka S, Tamai N, Ikematsu $\mathrm{H}$ et al. Improved visibility of colorectal flat tumors using image-enhanced endoscopy. Dig Endosc 2015; 27: $35-39$

[16] Uraoka T, Saito Y, Matsuda T et al. Endoscopic indications for endoscopic mucosal resection of laterally spreading tumours in the colorectum. Gut 2006; 55: $1592-1597$

[17] Kudo SE, Kashida H. Flat and depressed lesions of colorectum. Clin Gastroenterol Heptol 2005; 3 (7 Suppl. 1) S33-S36

[18] Participants in the Paris Workshop. The Paris endoscopic classification of superficial neoplastic lesions: esophagus, stomach, and colon: November 30 to December 1, 2002. Gastrointest Endosc 2003; 58 : (Suppl. 06): S3-43

[19] Kudo $S$ et al. Nonpolypoid neoplastic lesions of the colorectal mucosa. Gastrointest Endosc 2008; 68: (Suppl. 04): S3-47

[20] Ikematsu H, Matsuda T, Emura F et al. Efficacy of capillary pattern type IIIA/IIIB by magnifying narrow band imaging for estimating depth of invasion of early colorectal neoplasms. BMC Gastroenterol 2010; 10: 33

[21] Kudo S, Rubio CA, Texeira CR et al. Pit pattern in colorectal neoplasia: endoscopic magnifying view. Endoscopy 2001; 33: 367-373

[22] Bosman FT, Carneiro F, Hruban RH, Theise ND. WHO classification of tumours of the digestive system. 4th ed. Lyon; France: IARC Press; 2010

[23] Kaku E, Oda Y, Murakami Y et al. Proportion of flat- and depressedtype and laterally spreading tumor among advanced colorectal neoplasia. Clin Gastroenterol Hepatol 2011; 9: 503-508

[24] Ikematsu H, Saito Y, Tanaka S et al. The impact of narrow band imaging for colon polyp detection: a multicenter randomized controlled trial by tandem colonoscopy. J Gastroenterol 2012; 47: 1099-1107

[25] Hewett DG, Kaltenbach T, Sano Y et al. Validation of a simple classification system for endoscopic diagnosis of small colorectal polyps using narrow-band imaging. Gastroenterology 2012; 143: 599-607.e1

[26] Matsuda T, Fujii T, Sano Y et al. Randomized comparison of surveillance intervals after colonoscopic removal of adenomatous polyps: Results from the Japan Polyp Study. Gastroenterology 2014; 146: S161-162

[27] Leung WK, Lo OS, Liu KS. Detection of colorectal adenoma by narrow band imaging (HQ190) vs. high-definition white light colonoscopy: a randomized controlled trial. Am J Gastroenterol 2014; 109: 855-863

[28] Horimatsu T, Sano Y, Tanaka $S$ et al. Next-generation narrow band imaging system for colonic polyp detection: a prospective multicenter randomized trial. Int J Colorectal Dis 2015; 30: 947 - 954

[29] Shimoda R, Sakata Y, Fujise T et al. The adenoma miss rate of blue-laser imaging vs. white-light imaging during colonoscopy: a randomized tandem trial. Endoscopy 2017; 49: $186-190$

[30] Ikematsu H, Sakamoto T, Togashi K et al. Detectability of colorectal neoplastic lesions using a novel endoscopic system with blue laser imaging: a multicenter randomized controlled trial. Gastrointest Endosc 2017; 86: 386 - 394 